\title{
Influence of Isothermal Treatment Prior to Initial Quenching of Q\&P Process on Microstructure and Mechanical Properties of Medium Mn Steel
}

\author{
Ji Hoon KIM, ${ }^{1)}$ Min-Hyeok KWON, ${ }^{1)}$ Jae Sang LEE, ${ }^{1)}$ Seawoong LEE, ${ }^{2)}$ Kyooyoung LEE') and Dong-Woo SUH ${ }^{11 *}$ \\ 1) Graduate Institute of Ferrous Technology, Pohang University of Science and Technology, Pohang, 37673 Republic of Korea. \\ 2) Technical Research Laboratories, POSCO, Gwangyang, Republic of Korea.
}

(Received on November 14, 2019; accepted on January 14, 2020)

\begin{abstract}
The influence of isothermal treatment prior to the initial quenching step of Q\&P process was investigated in $0.26 \mathrm{C}-4.15 \mathrm{Mn}-1.39 \mathrm{Si}$ steel. Compared to the microstructure of the Q\&P processed steel: a mixture of martensite and retained austenite, the microstructure subjected to isothermal treatment before initial quenching step (BQ\&P) consists of bainitic ferrite, martensite and retained austenite. Formation of bainitic ferrite during isothermal treatment refined the retained austenite grain size and made the filmy morphology prevalent in the final microstructure. Besides, carbon effectively enriched into the austenite adjacent the bainitic ferrite. The change in size, morphology and carbon content enhanced the mechanical stability of austenite in BQ\&P processed steel; it has a beneficial influence on improving tensile elongation for a given tensile strength level. Moreover, controlling austenite characteristics by isothermal treatment is advantageous on the stretch-flangeability; hole expansion ratio is evaluated to be $22.2 \%$ for BQ\&P processed steel, which is 2.7 time higher than that for the conventional O\&P processed one.
\end{abstract}

KEY WORDS: quenching and partitioning (Q\&P); bainite; filmy austenite; hole expansion ratio; austenite stability.

\section{Introduction}

Quenching and partitioning (Q\&P) processed steel which was proposed by Speer et al. ${ }^{1}$ is a promising material for the automotive applications. The Q\&P process consists of following procedures: a steel sheet is fully or partially austenitized (annealing step) and quenched to temperature $\mathrm{T}_{\mathrm{Q}}$, between $\mathrm{M}_{\mathrm{s}}$ and $\mathrm{M}_{\mathrm{f}}$ for partial transformation of martensite (initial quenching step). Then, the sheet is held at $\mathrm{T}_{\mathrm{Q}}$ or higher temperature $T_{P}$ (partitioning step) followed by cooling to room temperature; this step allows the redistribution of supersaturated carbon in martensite into austenite.

A wide range of mechanical properties can be obtained by controlling annealing temperature $\left(\mathrm{T}_{\mathrm{A}}\right)$, quenching temperature $\left(T_{Q}\right)$, and partitioning temperature $\left(T_{P}\right){ }^{2-8)}$ Indeed, those parameters determine the stability of retained austenite, which plays a critical role in obtaining desired mechanical properties. Stable austenite can exhibit transformation induced plasticity (TRIP) effect up to highly strained state, ${ }^{4,5)}$ contributing to a good combination of strength and elongation. The stability of the austenite is mainly governed

\footnotetext{
* Corresponding author: E-mail: dongwoo1@postech.ac.kr
}

by carbon concentration, grain size, and morphology. ${ }^{9-14)}$ Compared to the intensive studies on the effect of initial quenching and partitioning condition which affects carbon concentration, and the annealing condition which affects grain size, the influence of process parameters on the morphology of austenite has drawn less attention. Actually, the film type austenite is reported to have beneficial effect on the mechanical properties than the blocky type, ${ }^{2,10,15-17)}$ and decreasing the initial quenching temperature $T_{Q}$ enhances the evolution of filmy austenite. However, low $\mathrm{T}_{\mathrm{Q}}$ causes the decrease of the retained austenite fraction $\left(\mathrm{V}_{\gamma}\right)$ as well; it has a detrimental influence on the tensile property due to less TRIP effect. ${ }^{2,11)}$ In that sense, in controlling the morphology of austenite, keeping the appropriate fraction is a critical accompanying issue.

Gui et al. obtained nanometer-sized filmy austenite with a fraction of 0.3 by introducing isothermal treatment before the initial quenching step. They reported an impressive combination of tensile strength (TS) of $1495 \mathrm{MPa}$ and total elongation $(\mathrm{El})$ of $31.8 \%$ in $0.4 \mathrm{C}-2.1 \mathrm{Mn}-1.7 \mathrm{Si}-0.4 \mathrm{Cr}$ steel. ${ }^{18)}$ It is called as bainite-based quenching and partitioning process (BQ\&P). Not only tensile properties but also impact toughness was significantly improved using the 
BQ\&P process. ${ }^{15)}$ Gao et al. reported that BQ\&P processed steel having nanometer-sized filmy austenite exhibited impact toughness of $82 \mathrm{~J} / \mathrm{cm}^{2}$ and $48 \mathrm{~J} / \mathrm{cm}^{2}$ at room temperature and $-40^{\circ} \mathrm{C}$, respectively, while bainitic austempered (BAT) processed steel containing the blocky austenite showed $28 \mathrm{~J} / \mathrm{cm}^{2}$ and $7 \mathrm{~J} / \mathrm{cm}^{2}$. Interestingly, compared to the impact property, the tensile properties did not show remarkable difference: TS of $1688 \mathrm{MPa}$ and $\mathrm{El}$ of $17.6 \%$ in BQ\&P processed steel and TS of $1505 \mathrm{MPa}$ and T.El of 14\% in BAT processed one.

Recently, stretch flangeability attracts keen interest in high strength steels; it is the ability to resist a failure from localized deformation at sheared edge and quantified by hole expansion ratio (HER). There is a trade-off between the tensile property and stretch flangeability in steels containing retained austenite. Better stretch flangeability can be obtained in fine, homogeneous microstructure because the interface between hard and soft phase is vulnerable to cracking under localized deformation; ${ }^{19-21)}$ therefore the presence of large amount of austenite will deteriorate the stretch flangeability even though it is advantageous to enhance the TRIP effect.

In that context, it is worth investigating the microstructure evolution and characteristics of austenite subjected to the BQ\&P process and its influence on the stretch flangeability as well as the tensile property. For that purpose, we chose the medium Mn steel in this study. It is because, as mentioned, the influence of austenite morphology is not fully explored subject in the medium Mn steel; moreover, the morphology control is expected to provide a clue to reconcile mutually exclusive properties.

\section{Experimental Procedure}

Chemical composition of investigated steel is Fe-0.26C 4.15Mn - 1.39Si (in wt.\%). The specimen was prepared as cold-rolled sheet with a thickness of $1.2 \mathrm{~mm}$. The initial microstructure was a mixture of deformed pearlite and martensite. Dissimilar heat treatments were applied to change the morphology of austenite. One is a conventional Q\&P process and the other is a process involving an isothermal treatment prior to the initial quenching of the Q\&P process (BQ\&P). For the conventional Q\&P process, the specimen was fully austenitized at $870^{\circ} \mathrm{C}$ for $4 \mathrm{~min}$ in a box furnace and quenched to $150^{\circ} \mathrm{C}$ using an oil bath. Then, the specimen was heated to $450^{\circ} \mathrm{C}$ and partitioning treated for $3 \mathrm{~min}$ in a salt bath, followed by water quenching to room temperature. For the $\mathrm{BQ} \& \mathrm{P}$ process, the specimen was fully austenitized at $870^{\circ} \mathrm{C}$ for $4 \mathrm{~min}$ in a box furnace and quenched to $300^{\circ} \mathrm{C}$ in a salt bath, and subjected to isothermal treatment for $2 \mathrm{~h}$ to introduce bainitic ferrite. Note that the temperature for isothermal treatment is slightly above the martensite start temperature $\left(\mathrm{M}_{\mathrm{s}}\right)$. Subsequently, the specimen was quenched to $90^{\circ} \mathrm{C}$ using an oil bath and then heated for partitioning treatment at $450^{\circ} \mathrm{C}$ for $3 \mathrm{~min}$ before water-quenching to room temperature. To make sure that temperature follow the designed heat treatment, a thermocouple was attached to the steel during the heat cycle. Different quenching temperature $\left(\mathrm{T}_{\mathrm{Q}}\right)$ was devised to obtain similar austenite fraction $\left(\mathrm{V}_{\gamma}\right)$ in final microstructure. The heat treatment cycles (Q\&P and BQ\&P) are schematically illustrated in Fig. 1.

Dilatometry was conducted to monitor the phase transformation along the heat treatment. A pushrod type quenching dilatometer was used with a specimen of $10 \mathrm{~mm} \times 5$ $\mathrm{mm} \times 1.2 \mathrm{~mm}$. The heating and cooling rates were set to simulate the heat treatments in the box furnace, oil bath, and salt bath. The microstructure was characterized by using a field emission scanning electron microscopy (FE-SEM) with electron backscatter diffraction (EBSD) and a field emission transmission electron microscopy (FE-TEM). The specimen was electro-chemically polished in a solution of $5 \% \mathrm{HClO}_{4}+95 \% \mathrm{CH}_{3} \mathrm{COOH}$ for SEM and EBSD analysis. The EBSD data with a minimum confidence index (CI) value of 0.1 were used for the analysis. For TEM observation, a specimen was prepared as a $3 \mathrm{~mm}$ disc and electro-chemically polished by using a twin-jet polisher with a solution of $5 \%$ $\mathrm{HClO}_{4}+95 \% \mathrm{CH}_{3} \mathrm{COOH}$. Three-dimensional atom probe tomography (3DAPT) was used to examine the distribution of alloy element in the complex microstructure. The 3DAPT was conducted using a laser-assisted atom probe with a specimen prepared by a focused ion beam (FIB) technique. The austenite fraction $\left(\mathrm{V}_{\gamma}\right)$ was estimated by integrating intensity of $(111)_{\gamma},(200)_{\gamma},(220)_{\gamma},(311)_{\gamma}$ and $(110)_{\alpha},(200)_{\alpha},(211)_{\alpha}$, $(220)_{\alpha}$ peaks obtained from XRD. The carbon concentration in the retained austenite was assessed by using following equation with a lattice parameter of austenite evaluated from $(200)_{\gamma}$ peak. $^{4)}$

$$
\begin{aligned}
a_{\gamma}(\mathrm{nm})= & 0.3556+0.00453 \mathrm{C}+0.000096 \mathrm{Mn}-0.00002 \mathrm{Ni} \\
& +0.00006 \mathrm{Cr}+0.00056 \mathrm{Al}+0.00031 \mathrm{Mo} \\
& +0.00018 \mathrm{~V}(\text { wt. } \%)
\end{aligned}
$$

The specimen for XRD measurement was prepared using a solution of $10 \%$ of $\mathrm{HF}+90 \%$ of $\mathrm{H}_{2} \mathrm{O}_{2}$ to eliminate possible decarburizing layer.

The tensile test was conducted using an ASTM E8M subsize specimen with the gauge length of $25 \mathrm{~mm}$ at a strain rate of $0.001 \mathrm{~s}^{-1}$. The stretch-flangeability was evaluated using a hole expansion test (HET) with $90 \mathrm{~mm} \times 90 \mathrm{~mm} \times$ $1.2 \mathrm{~mm}$ specimen. A hole with a diameter of $10 \mathrm{~mm}$ was made in the specimen center by punching with a clearance of $20 \%$. The test was conducted using a $60^{\circ}$ conical punch

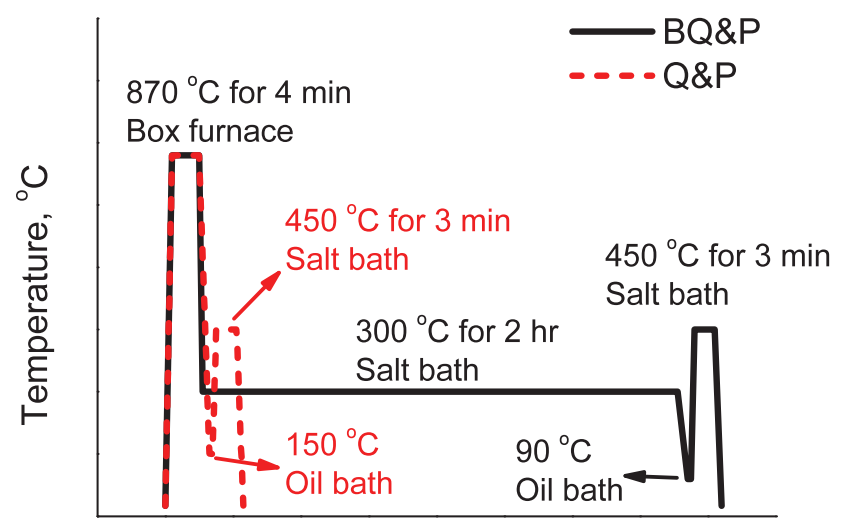

Time

Fig. 1. Heat treatment cycles of bainitic based quenching and partitioning $(\mathrm{BQ} \& \mathrm{P})$ process and conventional two-step quenching and partitioning $(\mathrm{Q} \& \mathrm{P})$ process. (Online version in color.) 
at a speed of $8 \mathrm{~mm} / \mathrm{min}$. The specimen was fixed with blank holding force of $200 \mathrm{kN}$. The test was stopped when a crack fully penetrated through the thickness direction. The HER was evaluated by following equation.

$$
\operatorname{HER}(\%)=\frac{D_{f}-D_{0}}{D_{0}} \times 100
$$

Here, $\mathrm{D}_{0}$ and $\mathrm{D}_{\mathrm{f}}$ is the hole diameter before and after the test, respectively.

\section{Results and Discussion}

\subsection{Microstructure}

A schematic illustration of microstructure evolution during BQ\&P process is shown in Fig. 2. After full austenitization upon annealing, bainitic transformation proceeds during isothermal treatment. The microstructure will evolve into $\alpha_{\mathrm{BF}}+\gamma_{\mathrm{Block}}+\gamma_{\mathrm{A}}$, where $\alpha_{\mathrm{BF}}$ is bainitic ferrite, $\gamma_{\mathrm{A}}$ is filmy austenite between bainitic ferrite; it can be stabilized during the isothermal treatment, and $\gamma_{\text {Block }}$ is the residual austenite where bainitic ferrite is not present (Fig. 2). Upon initial quenching to $\mathrm{T}_{\mathrm{Q}}\left(90^{\circ} \mathrm{C}\right)$, the $\gamma_{\text {Block }}$ further transforms into martensite $\left(\alpha^{\prime}\right)$ due to lack of stability, leaving another type of austenite $\left(\gamma_{M}\right){ }^{22)}$ It should be noted that $\gamma_{\mathrm{A}}$ and $\gamma_{\mathrm{M}}$ are formed at different heat treatment steps. After carbon partitioning from $\alpha^{\prime}$ to $\gamma_{\mathrm{M}}$ at $\mathrm{T}_{\mathrm{P}}\left(450^{\circ} \mathrm{C}\right)$, the final microstructure of $\mathrm{BQ} \& \mathrm{P}$ processed steel is composed of $\gamma_{\mathrm{A}}+$ $\gamma_{\mathrm{M}}+\alpha_{\mathrm{BF}}+\alpha^{\prime}$

The phase fraction according to this scenario is quantified with dilatometry and microstructure characterization. Firstly, the microstructure evolution during conventional Q\&P process is considered by dilatometry (Fig. 3(a)). In the initial quenching step, martensite transformation started around $280^{\circ} \mathrm{C}$. Bainite transformation was negligible in the subsequent partitioning step $\left(450^{\circ} \mathrm{C}\right.$ for $\left.3 \mathrm{~min}\right)$ but the carbon partitioning effectively stabilized the austenite, suppressing the formation of martensite during final cooling. Final microstructure is $\gamma+\alpha^{\prime}$; the austenite fraction is 0.21 evaluated by XRD analysis. Figure 3(b) shows the dilatation along BQ\&P process. In the isothermal treatment $\left(300^{\circ} \mathrm{C}\right.$ for $2 \mathrm{~h}$ ), a remarkable volume expansion was monitored, indicating the formation of bainitic ferrite. In the next cooling step, martensite transformation started around $235^{\circ} \mathrm{C}$, which is lower than that in the Q\&P process; it is led by the carbon enrichment to austenite during the formation of bainitic

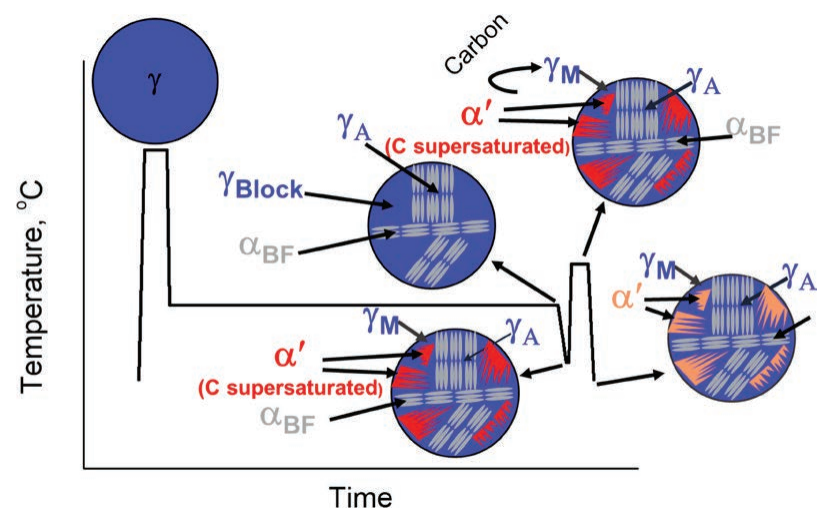

Fig. 2. Schematic illustration of microstructural evolution during BQ\&P process. (Online version in color.) ferrite. ${ }^{15)}$ The decrease in $\mathrm{M}_{\mathrm{s}}$ temperature corresponds to the increment of carbon content by $0.11 \mathrm{wt} . \%$ based on the empirical equation $\left(\mathrm{M}_{\mathrm{s}}=539-423 \mathrm{C}-30.4 \mathrm{Mn}-7.5 \mathrm{Si}+\right.$ $30 \mathrm{Al}$ (in wt. $\%)^{23)}$ ). Meanwhile, further bainite formation was hardly observed during the partitioning step and martensite transformation did not occur in final cooling. The dilatation in Fig. 3(b) is consistent with the scenario of microstructure evolution in Fig. 2, suggesting the final microstructure of $\gamma$ $\left(\gamma_{\mathrm{A}}\right.$ and $\left.\gamma_{\mathrm{M}}\right)+\alpha_{\mathrm{BF}}+\alpha^{\prime}$. The XRD analysis reveals that the austenite fraction is 0.21 , nearly same to that of the Q\&P
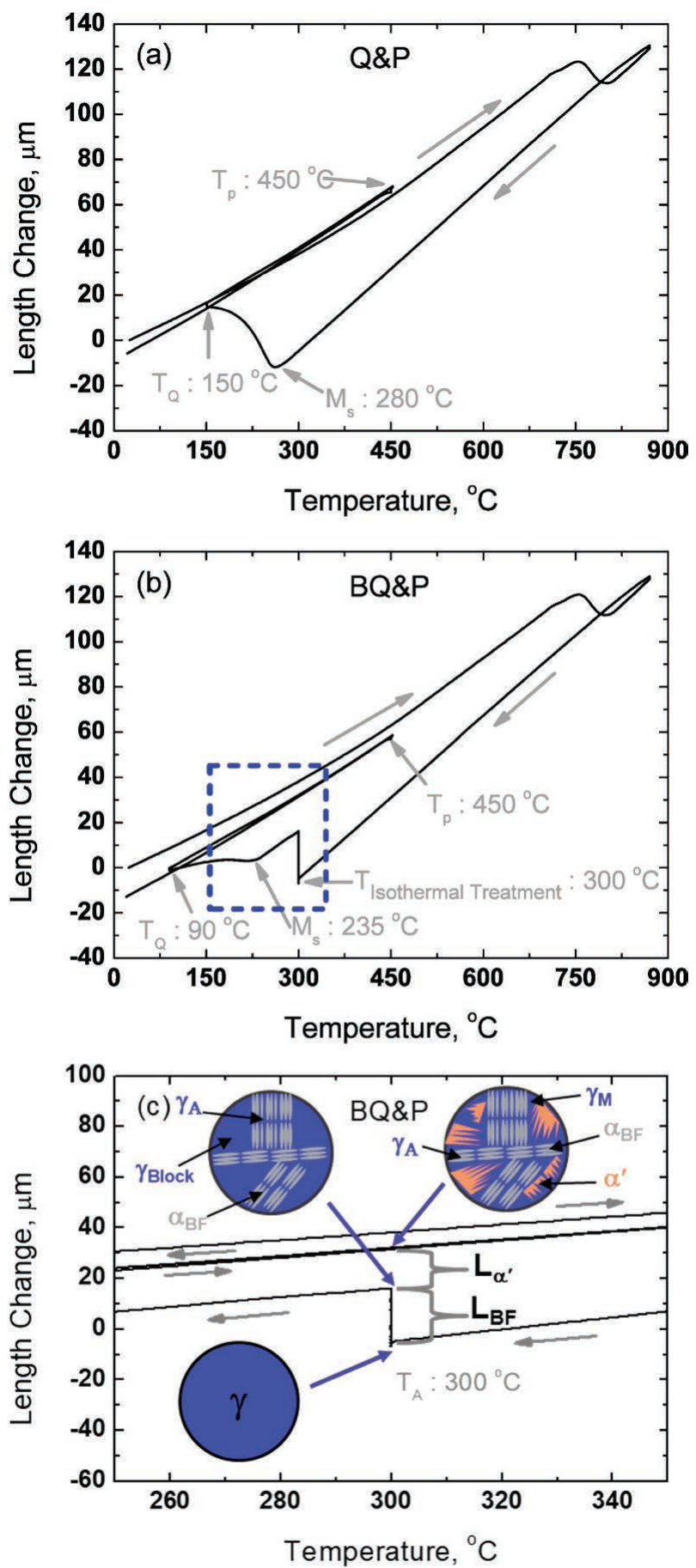

Fig. 3. (a) Dilatation during conventional two-step Q\&P process and (b) during BQ\&P process. (c) Magnified image of blue dotted area in (b) and schematic illustration of microstructure at $300^{\circ} \mathrm{C}$ upon BQ\&P process. Dilatations caused by bainitic and martensitic transformation are indicated as $\mathrm{L}_{\mathrm{BF}}$ and $\mathrm{L}_{\alpha}$. (Online version in color.) 
processed one.

While the microstructure of Q\&P processed steel is simply composed of $\gamma$ and $\alpha^{\prime}$, the microstructure subjected to $\mathrm{BQ} \& \mathrm{P}$ process is rather complicated. It requires further analysis for the microstructure characterization. We attempt to quantify the fraction of bainitic ferrite $\left(\mathrm{V}_{\mathrm{BF}}\right)$ and martensite $\left(\mathrm{V}_{\alpha^{\prime}}\right)$ in BQ\&P processed microstructure as follows. Figure 3(c) magnifies the blue dotted part in Fig. 3(b). As indicated schematically, the microstructure would be the austenite single phase at the beginning of isothermal treatment. Formation of bainitic ferrite proceeds as time elapses, generating a dilatation noted as $\mathrm{L}_{\mathrm{BF}}$ in Fig. 3(c). After isothermal treatment, the specimen volume is expanded by formation of martensitic during quenching to $\mathrm{T}_{\mathrm{Q}}\left(90^{\circ} \mathrm{C}\right)$. Consequently, in the course of heating to the partitioning temperature, the dilatation $\mathrm{L}_{\alpha^{\prime}}$ in Fig. 3(c) is the length change led by the formation of martensite. Then, as long as further transformation is negligible in the partitioning step and the final cooling, the fraction of bainitic ferrite and martensite can be approximated,

$$
\begin{gathered}
V_{B F}+V_{\alpha^{\prime}}=0.79 \\
V_{B F}=\frac{L_{B F}}{L_{B F}+L_{\alpha^{\prime}}}\left(V_{B F}+V_{\alpha^{\prime}}\right) \\
V_{\alpha^{\prime}}=\frac{L_{\alpha^{\prime}}}{L_{B F}+L_{\alpha^{\prime}}}\left(V_{B F}+V_{\alpha^{\prime}}\right)
\end{gathered}
$$

Table 1 shows the $\mathrm{V}_{\mathrm{BF}}$ and $\mathrm{V}_{\alpha^{\prime}}$ determined by averaging 5 dilatation results.

Apart from the bainitic ferrite and martensite, there are different kinds of austenite in the BQ\&P processed microstructure; one is the austenite being able to be stabilized dur-

\begin{tabular}{|c|c|c|}
\hline Process & FCC & $\mathrm{BCC}$ \\
\hline BQ\&P & $\mathrm{V}_{\gamma \mathrm{A}} 0.12 \quad \mathrm{~V}_{\gamma \mathrm{M}} 0.09$ & $\mathrm{~V}_{\alpha \mathrm{BF}} 0.42 \quad \mathrm{~V}_{\alpha} 0.37$ \\
\hline Q\&P & $\mathrm{V}_{\gamma} 0.21$ & $\mathrm{~V}_{\alpha^{\prime}} 0.79$ \\
\hline
\end{tabular}

Table 1. Constituent phase fraction of BQ\&P and Q\&P processed steels. ing isothermal treatment $\left(\gamma_{\mathrm{A}}\right)$ and the other is the austenite retained after initial quenching and stabilized by partitioning treatment $\left(\gamma_{M}\right)$. The $\gamma_{M}$ originally belongs to the $\gamma_{\text {Block }}$ where the bainitic ferrite is not formed during isothermal treatment (Fig. 2); indeed, $\gamma_{\text {Block }}$ is the region mainly affected by the quenching and partitioning treatment. Figure 4 shows the interrupt-quenched microstructure after the isothermal treatment at $300^{\circ} \mathrm{C}$ for $2 \mathrm{~h}$. The SEM micrograph and EBSD phase map in Figs. 4(a) and 4(b) effectively reveal the region where the bainitic ferrite transformation prevails; it is more responsive to the etchant and exhibits rough surface. On the other hand, blocky regions with smooth surface is martensite identified as BCC crystal structure in EBSD map; it was transformed from $\gamma_{\text {Block }}$ during the interrupt quenching. There are austenite grains that can be regarded as $\gamma_{\mathrm{A}}$ in Fig. 4(b) but it is noted that the nanometer-sized filmy $\gamma_{\mathrm{A}}$ are also present between bainitic ferrite, which is hard to be detected in EBSD due to the limit of resolution. ${ }^{15,24)}$ The region covered by bainitic ferrite can be distinguished as well by Kernel average misorientation (KAM) map (Fig. 4(c)). The region with low KAM value (blue) matches with the bainitic ferrite. It is possibly because bainitic ferrite has lower dislocation density than martensite (green). The 3DAPT analysis provides distinct feature in constituent phases in terms of the chemistry (Fig. 5). Even though the redistribution of substitutional elements is negligible, the partitioning of carbon accompanying the formation of bainitic ferrite is evident. The average carbon concentration in austenite next to bainitic ferrite, presumed to be nanosized filmy $\gamma_{\mathrm{A}}$, is approximately $1.2 \mathrm{wt} . \%$; it is high enough for stabilization. Interestingly, there is a region where the carbon concentration is around $0.4 \mathrm{wt} . \%$ that is higher than the nominal carbon content of the steel. A mild enrichment of carbon suggests that it belongs to the martensite that

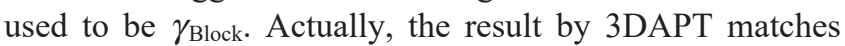
well with the carbon concentration of $0.37 \mathrm{wt} \%$ in $\gamma_{\text {Block, }}$ estimated from the decrement of $\mathrm{M}_{\mathrm{s}}$ temperature (Fig. 3(b)).

As mentioned, the $\mathrm{BQ} \& \mathrm{P}$ process produced two types of austenite stabilized by the isothermal treatment $\left(\gamma_{\mathrm{A}}\right)$ and by the partitioning step $\left(\gamma_{\mathrm{M}}\right)$, respectively. Since they are expected to have dissimilar characteristics, we quantify the
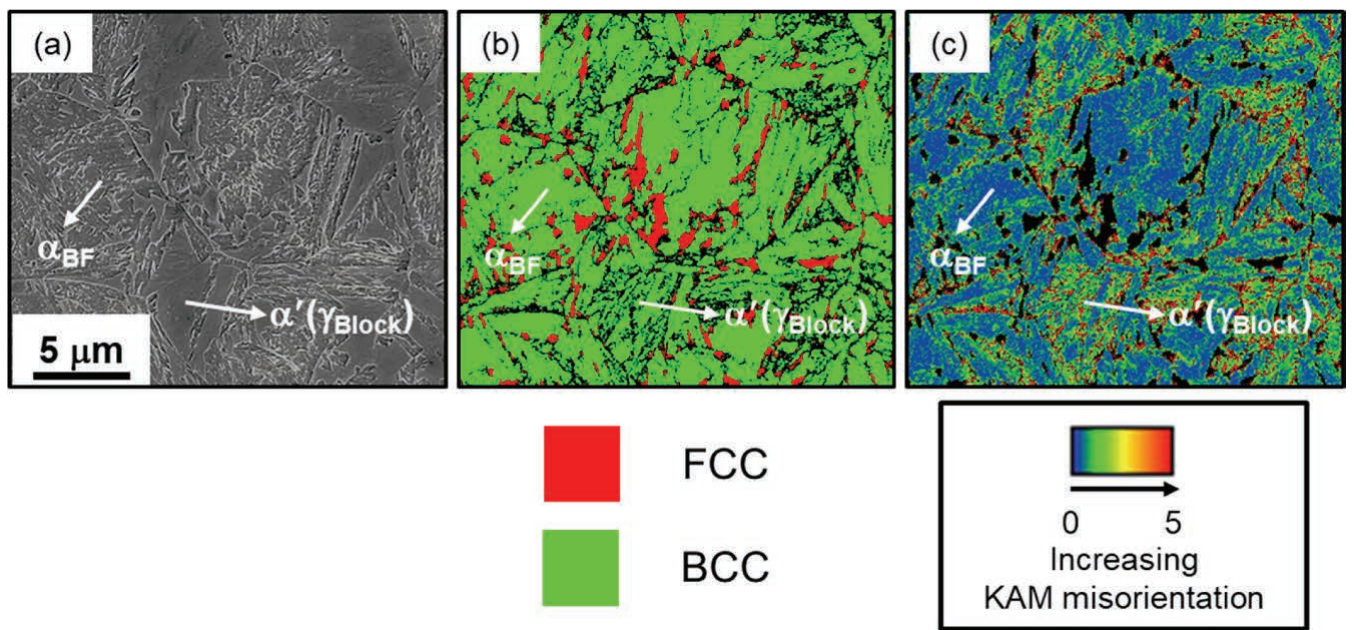

Fig. 4. Microstructure of the steel austempered at $300^{\circ} \mathrm{C}$ for $2 \mathrm{hr}$ and cooled to room temperature. (a) Scanning electron microscopy (SEM) micrograph (b) phase map (red: FCC, green: BCC) and (c) kernel average misorientation (KAM) map of BCC phase. (Online version in color.) 
respective fraction, $\mathrm{V}_{\gamma \mathrm{A}}$ and $\mathrm{V}_{\gamma \mathrm{M}}$. We already know followings from the dilatometry and XRD analysis;

$$
V_{B F}=0.42, V_{\alpha^{\prime}}=0.37, V_{\gamma A}+V_{\gamma M}=0.21
$$

Applying Koinstinen-Marburger equation for the initial quenching step; ${ }^{15,25,26)}$
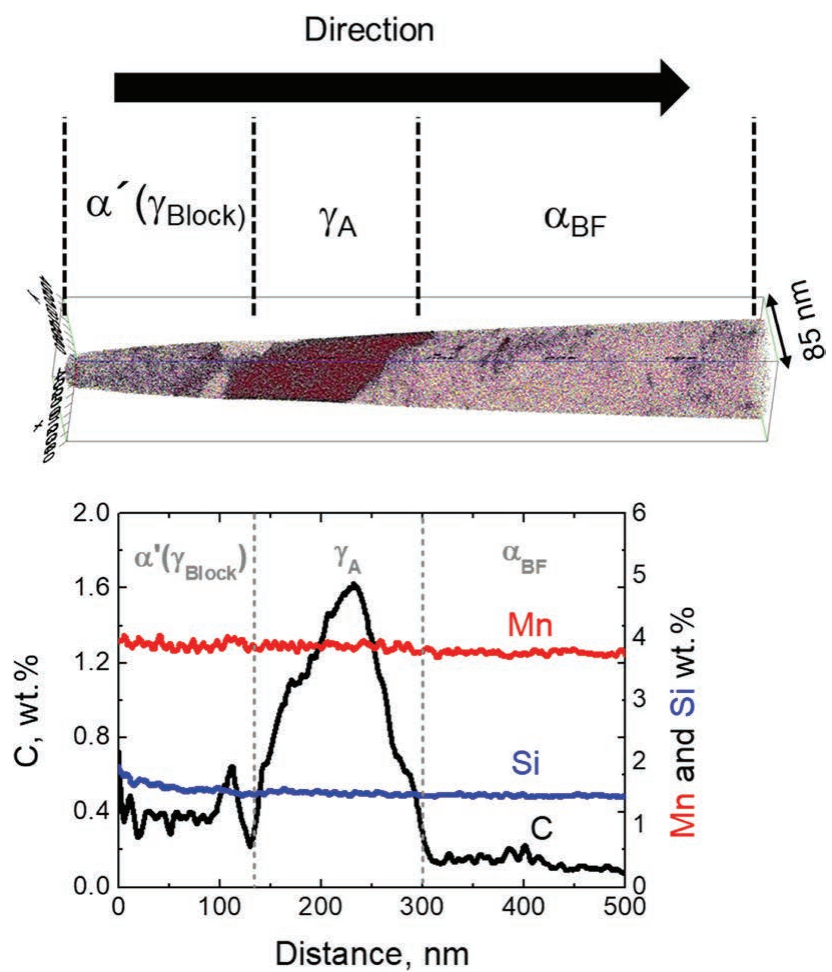

Fig. 5. Carbon atom mapping and alloy element profiles of the steel austempered at $300^{\circ} \mathrm{C}$ for $2 \mathrm{hr}$ and cooled to room temperature. (Online version in color.)
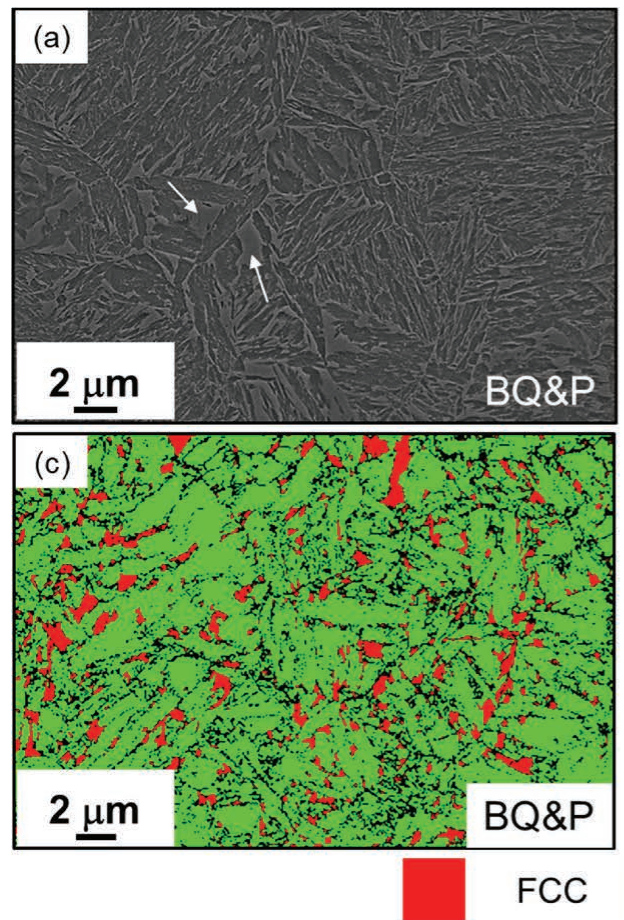

$$
\begin{aligned}
& V_{\alpha^{\prime}}=V_{\gamma \text { Block }} \cdot\left\{1-\exp \left[-\alpha\left(M_{s}-T_{Q}\right)^{\beta}\right]\right\} \\
& \alpha=0.076-0.182 \mathrm{C}+0.00014 \mathrm{Mn} \\
& \beta=1.4609+0.4483 \mathrm{C}-0.0545 \mathrm{Mn}
\end{aligned}
$$

$\mathrm{M}_{\mathrm{s}}=235^{\circ} \mathrm{C}, \mathrm{T}_{\mathrm{Q}}=90^{\circ} \mathrm{C}$ with the chemistry of $\gamma_{\mathrm{Block}}(\mathrm{C}=$ $0.37, \mathrm{Mn}=4.15$ wt. $\%$ ) give the fraction of $\mathrm{V}_{\gamma \text { Block }}=0.46$. Then, we can quantify the fraction of $\gamma_{M}$ and $\gamma_{A}$;

$$
V_{\gamma M}=V_{\gamma \text { Block }}-V_{\alpha^{\prime}}
$$

Table 1 summarizes the fraction of $\gamma_{\mathrm{A}}, \gamma_{\mathrm{M}}, \gamma_{\mathrm{BF}}$ and $\alpha^{\prime}$ in the final microstructure produced by the $\mathrm{BQ} \& \mathrm{P}$ process. Compared to the microstructure of conventional Q\&P process, the BQ\&P process generates considerable amount of bainitic ferrite; it also helps the retention of austenite stabilized in the isothermal treatment step.

Figures 6(a) and 6(b) show SEM microstructure produced by $\mathrm{BQ} \& \mathrm{P}$ and $\mathrm{Q} \& \mathrm{P}$ process, respectively. Even though some coarse austenite grains can be seen (white arrows), tiny austenite appears to prevail in the BQ\&P processed steel; whereas coarse and blocky austenite grains are frequently observed in the Q\&P condition. The EBSD phase maps also disclose the different size and morphology of retained austenite in the $\mathrm{BQ} \& \mathrm{P}$ and $\mathrm{Q} \& \mathrm{P}$ microstructure (Figs. 6(c) and 6(d)). Blocky austenite is more prevalent in the Q\&P condition; average size of austenite grain is evaluated to be $1.14 \mu \mathrm{m}$ and $0.68 \mu \mathrm{m}$ in the Q\&P and BQ\&P microstructure, respectively. This result accords with the earlier studies that the isothermal treatment prior to initial quenching is advantageous to obtain tiny, film type austenite. $^{27-29)}$

It is noted that coarse and blocky austenite can be refined even in the $\mathrm{Q} \& \mathrm{P}$ process by decreasing initial quenching temperature, $\mathrm{T}_{\mathrm{Q}}{ }^{2,11)}$ However, lowering quenching tempera-
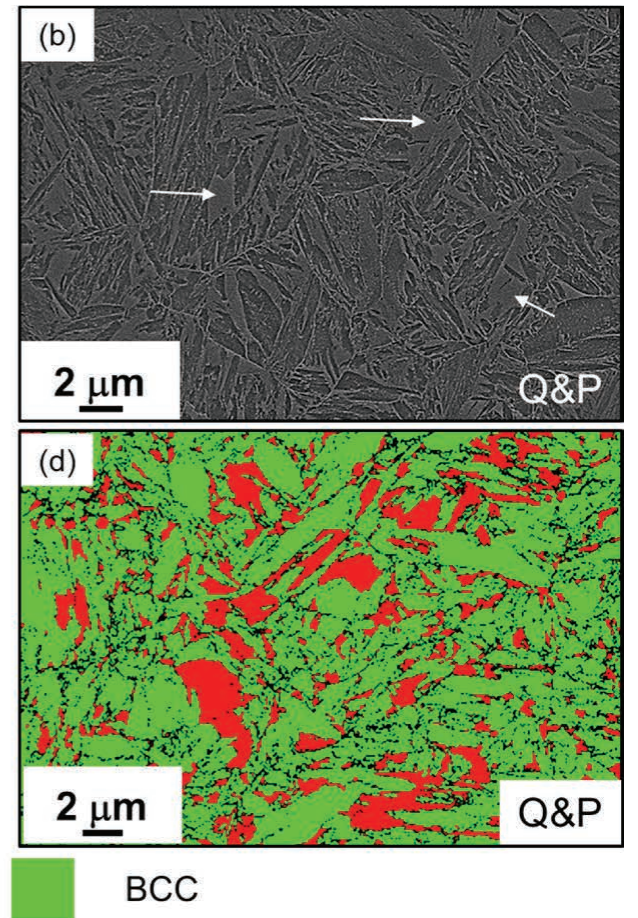

Fig. 6. Scanning electron microscopy (SEM) micrographs of (a) BQ\&P processed and (b) Q\&P processed steel both containing austenite fraction of 0.21 . White arrows indicate blocky type retained austenite. EBSD phase map of (c) BQ\&P processed and (d) Q\&P processed steel. (Online version in color.) 
ture in the Q\&P process inevitably decreases the fraction of austenite; it is not desired because a persistent TRIP effect is difficult to be expected with low austenite fraction. For instance, applying $\mathrm{T}_{\mathrm{Q}}$ of $90^{\circ} \mathrm{C}$ as an initial quenching temperature in $\mathrm{Q} \& \mathrm{P}$ process, the retained austenite fraction reduces to 0.08 which may not be enough to obtain TRIP effect. Therefore, it is important to notice that the BQ\&P process is beneficial because it gives a way to control the size and morphology of austenite while conserving its fraction.

Finally, it is worth mentioning the presence of nano-sized filmy austenite that is difficult to be captured in EBSD phase mapping. Figure 7(a) is a dark field image of nanometersized film austenite in the BQ\&P processed microstructure. Filmy austenite could be detected even in the Q\&P processed microstructure; however, rather coarse and blocky austenite was also frequently observed (Fig. 7(b)).

\subsection{Transformation Behavior during Tensile Test}

Figure 8 compared representative stress-strain curves depending on the process condition. Tensile strength (TS) and total elongation (El) of $\mathrm{BQ} \& \mathrm{P}$ processed steel are $1468 \pm 3 \mathrm{MPa}$ and $19.9 \pm 0.6 \%$; it has comparable properties to the Q\&P processed one, TS $1486 \pm 2 \mathrm{MPa}$ and El $16.8 \pm 0.3 \%$. However, yield strength (YS) in BQ\&P process $(1204 \pm 6 \mathrm{MPa})$ is higher than that in Q\&P condition $(1084 \pm 2 \mathrm{MPa})$. Microstructure refinement uncovered in the previous section primarily contribute to the better YS in the BQ\&P processed one. Not only the size and morphol-
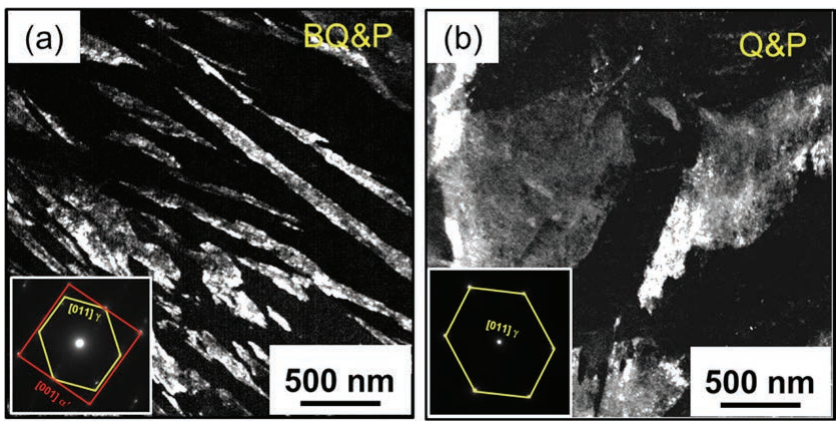

Fig. 7. Dark field image of the austenite in (a) BQ\&P processed (b) Q\&P processed steel. (Online version in color.)

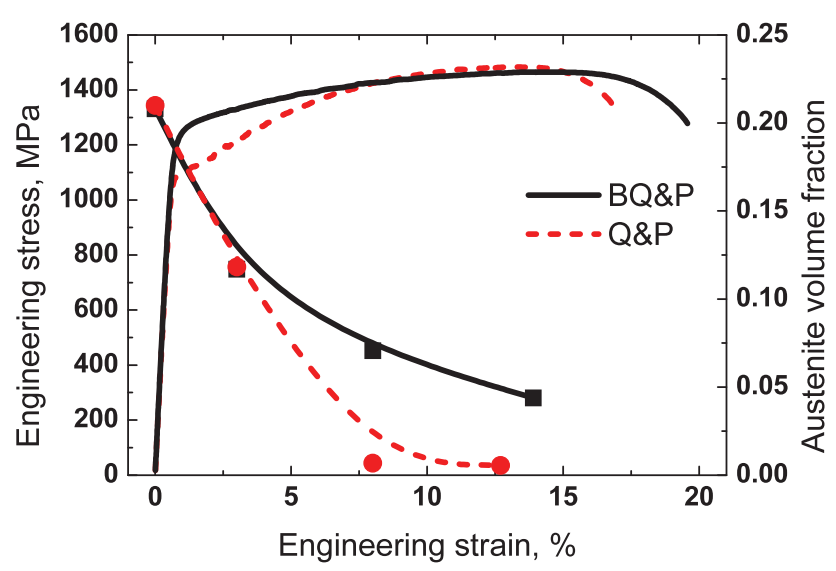

Fig. 8. Tensile curves of BQ\&P and Q\&P processed steel and the change of austenite fraction in the course of tensile deformation. (Online version in color.) ogy change in austenite but also splitting prior austenite grain by bainitic ferrite formation preceding to the initial quenching process is thought to enhance the refinement of final microstructure.

The change of austenite fraction in the course of tensile deformation is also given in Fig. 8. It was measured using XRD analysis on the tensile test coupon interrupted at engineering strain of 3\%,8\%, 13.9\% (uniform elongation, UE) for BQ\&P processed steel and 3\%,8\%, 12.7\% (UE) and for $\mathrm{Q} \& \mathrm{P}$ processed one. The austenite fraction is gradually decreased by strain-induced transformation in both cases, but the austenite subjected to the Q\&P process exhibits more drastic decrease; most of austenite is transformed to martensite at engineering strain of $8 \%$. Active formation of strain-induced martensite generates an intensive TRIP effect, leading to a notable work hardening at early stage of deformation. It explains similar level of tensile strengths in both cases even with lower yield strength in the Q\&P processed steel. However, it is noted that the strain-induced martensite transformation in BQ\&P processed steel provided more persistent TRIP effect by enhanced austenite stability, exhibiting better elongation compared to those in Q\&P processed one.

It is clear from the change of austenite fraction (Fig. 8) that the austenite stability is improved by the BQ\&P process. Figure 9 shows the $(200)_{\gamma}$ XRD peaks at tensile strain of
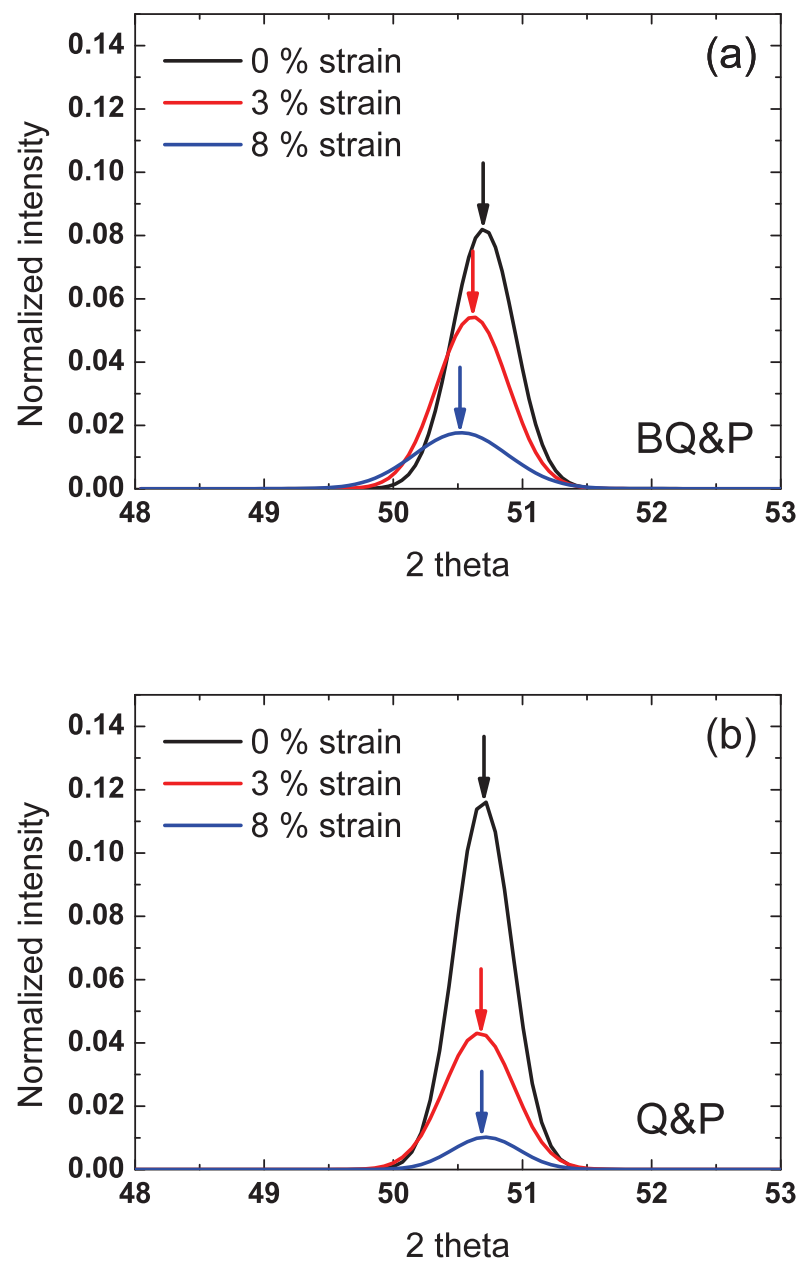

Fig. 9. $\quad \gamma(200)$ peak profile of (a) BQ\&P and (b) Q\&P processed steels subjected to tensile deformation interrupted at a strain of $0 \%, 3 \%$, and $8 \%$. (Online version in color.) 
$0 \%, 3 \%$ and $8 \%$. The peaks were smoothed and normalized for comparison of peaks from the specimens with different size. The decrease of peak intensity with the deformation is natural because the progress of strain-induced martensite transformation will decrease the austenite fraction. An interesting point is the peak position at each deformed conditions. In Q\&P processed steel, increasing tensile deformation reduces the peak intensity, but the peak position is nearly unaffected. The carbon concentration in the residual austenite is evaluated to be around $0.8-0.9$ wt.\% irrespective to the deformation. It suggests that the difference of carbon content among austenite grains is insignificant and the carbon is evenly distributed in austenite throughout the microstructure. Considering that the average grain size of austenite is $1.14 \mu \mathrm{m}$, the diffusion distance of carbon under the partitioning condition $\left(450^{\circ} \mathrm{C}\right.$ for $3 \mathrm{~min}$ ) estimated to be $1.2 \mu \mathrm{m},{ }^{7)}$ it is reasonable to explain uniform distribution in austenite grains. On the other hand, the position of $(200)_{\gamma}$ peak shifted to low angle side as the strain increased in the BQ\&P processed steel. Average carbon content in austenite is evaluated to be $0.84,0.97$ and $1.1 \mathrm{wt} . \%$ at strain of 0,3 and $8 \%$, respectively. It is noted that the nominal contents of Mn (4.15 wt.\%) and Si (1.39 wt.\%) were used for the calculation based on negligible partitioning confirmed in the 3DAPT (Fig. 5). It indicates that remaining austenite at strain of $8 \%$ has higher carbon concentration than that transformed into martensite in the course of straining. Regarding to the carbon redistribution, the main difference between $\mathrm{BQ} \& \mathrm{P}$ and $\mathrm{Q} \& \mathrm{P}$ process is the isothermal treatment allowing the formation of bainitic ferrite. Therefore, the variation of carbon content among austenite grains in BQ\&P condition is thought to be attributed to the effective carbon enrichment in austenite adjacent to the bainitic ferrite. Indeed, the average carbon content in a filmy austenite neighboring to the bainitic ferrite is evaluated to be 1.2 wt. $\%$ by 3DAPT (Fig. 5), which matches well with that in remaining austenite at strain of $8 \%$. It is noteworthy that the carbon redistribution into austenite is more encouraged by the isothermal treatment at $300^{\circ} \mathrm{C}$ than by the partitioning treatment at $450^{\circ} \mathrm{C}$. Longer time for isothermal treatment $(2$ h) than partitioning step ( $3 \mathrm{~min}$ ) can be one of reasons, but it is thought to be more related to the nature of bainitic ferrite formation which demands the redistribution of carbon to a certain extent for the progress of the transformation.

\subsection{Hole Expansion Ratio (HER)}

Stretch-flangeability assessed by hole expansion test (HET) is shown in Fig. 10. The BQ\&P processed steel exhibits 2.7 times higher hole expansion ratio (HER) than that of Q\&P processed one. The fracture surface by HET also shows dissimilar features depending on the process condition; ductile dimple surface in the BQ\&P steel but quasi-cleavage brittle fracture surface in the $\mathrm{Q} \& \mathrm{P}$ condition (Figs. 11(a) and 11(b)). It is noteworthy that the fracture surface subjected to the tensile test shows ductile dimples in both cases (Figs. 11(c) and 11(d)). A similar change from ductile to intergranular brittle fracture in the Q\&P steel was reported as the mechanical test was switched from a uniaxial tension to the double edge notched tension (DENT) ${ }^{30}$ )

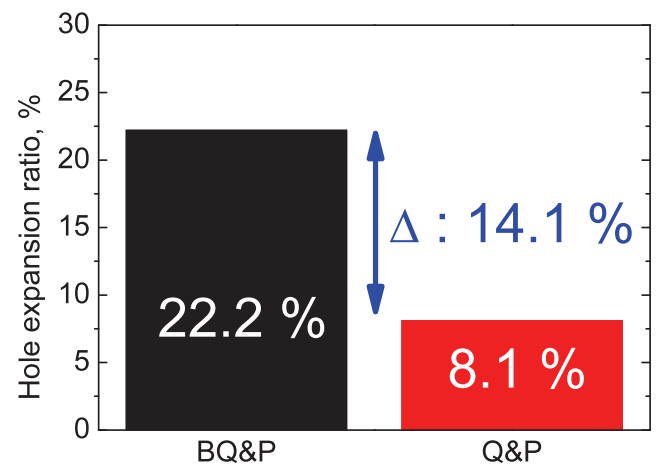

Fig. 10. Hole expansion ratio (HER) of BQ\&P and Q\&P processed steels. (Online version in color.)
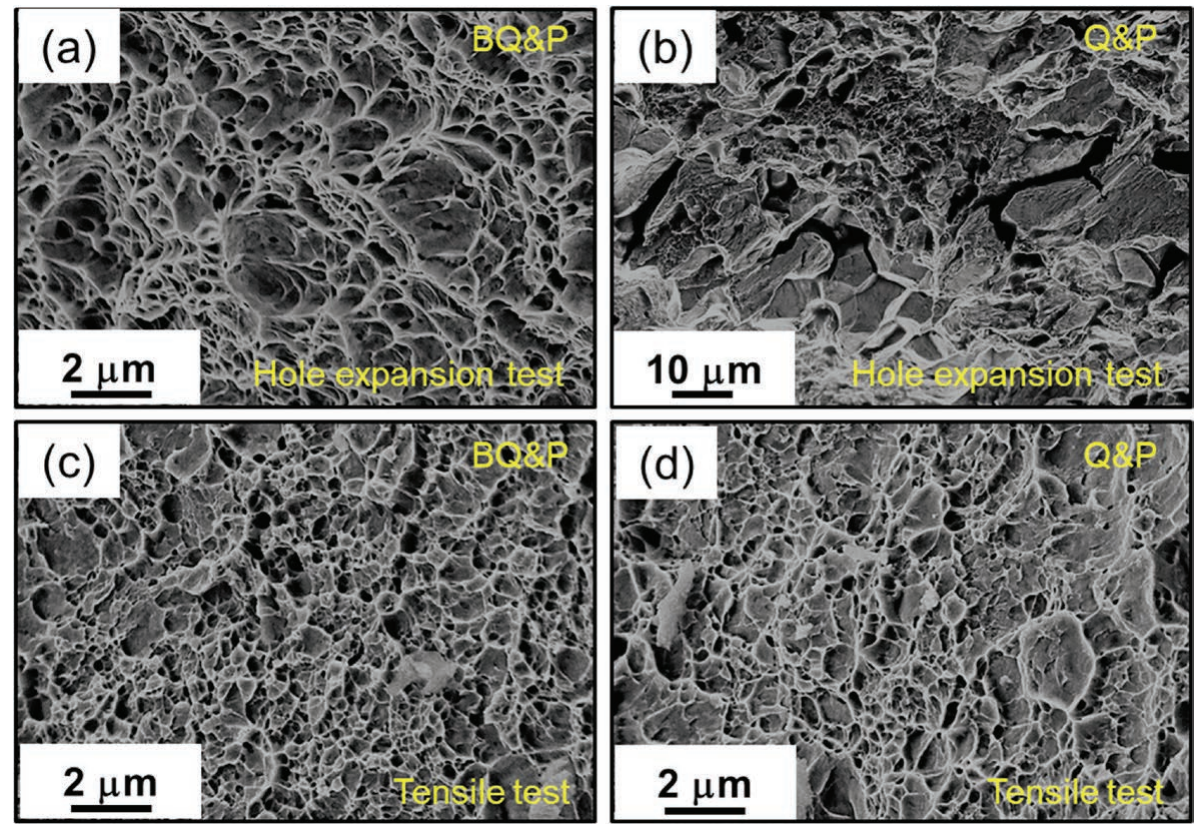

Fig. 11. Fractography of BQ\&P ((a) and (c)) and Q\&P ((b) and (d)) processed steels after hole expansion test and tensile test, respectively. (Online version in color.) 
Higher stress triaxiality in a DENT specimen was believed to cause faster transformation of austenite to martensite, making the steel prone to brittle fracture by crack propagation throughout the martensite.

A simulation using finite element method (FEM) indicated that the stress state at the edge of the hole during the HET is close to that of uniaxial tension, ${ }^{31,32)}$ but recent studies showed that the notch tensile test, which was a measure of resistance to crack propagation, corresponded well to the stretch flangeability evaluated by the HET using a punched hole. $^{33-36)}$ A shear affected zone (SAZ) is usually generated at the hole edge during the punching process; most of austenite in the SAZ is likely to transform into martensite due to large amount of deformation. ${ }^{2)}$ The SAZ possibly carries the micro-cracks, which are produced by formation of brittle martensite and subsequent deformation in the punching process, leading to earlier failure in HET. ${ }^{37-42)}$ Indeed, a closer look reveals the damages such as microcracks and voids in the vicinity of as-punched hole surface (fractured region) (Fig. 12). In that context, the HER using a specimen with punched hole is more related to the resistance to crack propagation; therefore the difference of the HER between BQ\&P and Q\&P processed steels $(14.1 \%)$ is primarily led by the dissimilar resistance to crack propagation during the HET.

Considering that the $\mathrm{BQ} \& \mathrm{P}$ and $\mathrm{Q} \& \mathrm{P}$ processed steels have a similar austenite fraction, it will be the characteristics of austenite in the BQ\&P condition, which suppress the brittle fracture and deterioration of HER. One of the most important features will be the size and morphology of austenite in the BQ\&P processed microstructure. Tiny and filmy austenite is more mechanically stable than coarse and blocky one. Moreover, it contains more carbon, the most important austenite stabilizing element, by active enrichment from the neighboring bainitic ferrite. The synergetic influence of size, morphology and chemistry will render the austenite more resistive to martensite transformation even in high stress triaxiality condition. It is also reported that the progress of crack tip could be effectively hindered by the presence of nanometer-sized filmy austenite because it could blunt and arrest the microcracks, ${ }^{15,18)}$ while blocky austenite could act as a site for formation of secondary cracks. ${ }^{43-46)}$ Besides, it is probable that the refined austenite grains uniformly distributed throughout the BQ\&P microstructure

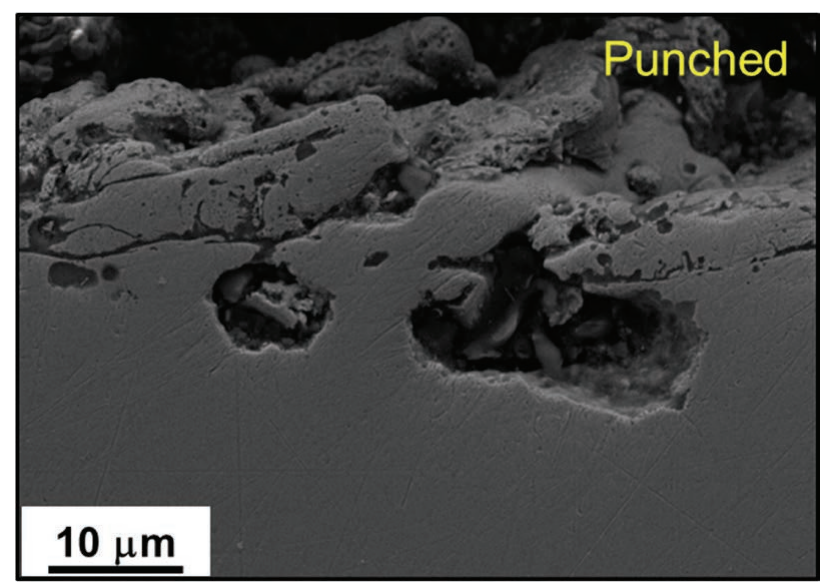

Fig. 12. Surface condition after punching. (Online version in color.) has a favorable influence in the stretch flangeability by less formation of damage during hole punching process; it may reduce the density of latent cracks in SAZ. Lastly, the formation of bainitic ferrite instead of martensite may have a positive influence of the HER in the BQ\&P processed steel. However, considering that the $\mathrm{BQ} \& \mathrm{P}$ processed steel exhibits a similar strength level to the Q\&P processed steel even though considerable amount of tempered martensite is replaced by bainitic ferrite in the former, the bainitic ferrite formed at low temperature $\left(\sim 300^{\circ} \mathrm{C}\right)$ is thought to have comparable strength to the tempered martensite in the Q\&P processed steel. In that context, the characteristics of austenite will have more dominant influence on the improvement of HER in the BQ\&P processed steel. Nevertheless, further quantitative investigation is necessary to confirm it.

\section{Conclusion}

The microstructure and mechanical properties were investigated $0.26 \mathrm{C}-4.15 \mathrm{Mn}-1.39 \mathrm{Si}$ steel subjected to the isothermal treatment prior to the initial quenching of Q\&P process.

(1) Compared to the microstructure of Q\&P processed steel: a mixture of martensite and retained austenite, the microstructure subjected to isothermal treatment before initial quenching step (BQ\&P) consists of bainitic ferrite, martensite and retained austenite. The grain size of austenite in final microstructure can be refined by applying the isothermal treatment in Q\&P process. Moreover, active carbon partitioning during bainitic ferrite formation makes the carbon content of adjacent filmy austenite $\left(\gamma_{\mathrm{A}}\right)$ higher than that of other austenite grains $\left(\gamma_{M}\right)$.

(2) The austenite in BQ\&P processed steel was more mechanically stable than that in Q\&P processed steel, which is led by the synergy of high carbon concentration, refined grain size and filmy morphology. Due to active TRIP effect even at highly strained state, the BQ\&P processed steel exhibits better elongation with equivalent strength level compared to the Q\&P processed steel. Controlling austenite characteristics by isothermal treatment also has a beneficial influence on the stretch-flangeability; hole expansion ratio is evaluated to be $22.2 \%$ in the BQ\&P processed steel which is 2.7 time higher than that in the Q\&P processed one.

\section{Acknowledgements}

The authors gratefully acknowledge the support of the POSCO Technical Research Laboratories.

\section{REFERENCES}

1) J. Speer, A. Streicher, D. Matlock, F. Rizzo and G. Krauss: Symp. on the Thermodynamics, Kinetics, Characterization and Modeling of Austenite Formation and Decomposition, ISS/TMS, Pennsylvania, (2003), 505.

2) J. H. Kim, E. J. Seo, M.-H. Kwon, S. Kang and B. C. De Cooman: Mater. Sci. Eng. A, 729 (2018), 276. https://doi.org/10.1016/ j.msea.2018.05.083

3) B. C. De Cooman, S. J. Lee, S. Shin, E. J. Seo and J. G. Speer: Metall. Mater. Trans. A, 48 (2017), No. 1, 39. https://doi.org/10.1007/ s11661-016-3821-z

4) E. J. Seo, L. Cho, Y. Estrin and B. C. De Cooman: Acta Mater., 113 (2016), 124. https://doi.org/10.1016/j.actamat.2016.04.048

5) L. Cho, E. J. Seo and B. C. De Cooman: Scr. Mater., 123 (2016), 69. https://doi.org/10.1016/j.scriptamat.2016.06.003

6) E. J. Seo, L. Cho and B. C. De Cooman: Metall. Mater. Trans. A, 45 (2014), No. 9, 4022. https://doi.org/10.1007/s11661-014-2657-7 
7) D. De Knijf, E. P. Da Silva, C. Föjer and R. Petrov: Mater. Sci. Technol., 31 (2015), No. 7, 817. https://doi.org/10.1179/17432847 14Y.0000000710

8) S. Kang, K. Kim, Y.-I. Son and S.-J. Lee: ISIJ Int., 57 (2016), 2057. https://doi.org/10.2355/isijinternational.ISIJINT-2016-257

9) D. De Knijf, C. Föjer, L. A. I. Kestens and R. Petrov: Mater. Sci. Eng. A, 638 (2015), 219. https://doi.org/10.1016/j.msea.2015.04.075

10) X. C. Xiong, B. Chen, M. X. Huang, J. F. Wang and L. Wang: Scr. Mater., 68 (2013), No. 5, 321. https://doi.org/10.1016/ j.scriptamat.2012.11.003

11) L. Liu, B. B. He, G. J. Cheng, H. W. Yen and M. X. Huang: Scr. Mater., 150 (2018), 1. https://doi.org/10.1016/j.scriptamat.2018.02.035

12) H.-S. Yang and H. K. D. H. Bhadeshia: Scr. Mater., 60 (2009), 493. https://doi.org/10.1016/j.scriptamat.2008.11.043

13) P. J. Jacques, F. Delannay and J. Ladrière: Metall. Mater. Trans. A, 32 (2001), No. 11, 2759. https://doi.org/10.1007/s11661-001-1027-4

14) E. Jimenez-Melero, N. H. van Dijk, L. Zhao, J. Sietsma, S. E. Offerman, J. P. Wright and S. van der Zwaag: Acta Mater., 55 (2007), No. 20, 6713. https://doi.org/10.1016/j.actamat.2007.08.040

15) G. Gao, H. Zhang, X. Gui, P. Luo, Z. Tan and B. Bai: Acta Mater., 76 (2014), 425. https://doi.org/10.1016/j.actamat.2014.05.055

16) Y. H. Choi, J. H. Ryu, S. W. Lee, K. Lee, B. J. Lee, J.-K. Kim, J. S. Lee and D.-W. Suh: Mater. Sci. Technol., 35 (2019), 2092. https:// doi.org/10.1080/02670836.2018.1475445

17) Y. Choi: Ph.D Thesis, Pohang University of Science and Technology, (2019).

18) X. Gui, G. Gao, H. Guo, F. Zhao, Z. Tan and B. Bai: Mater. Sci. Eng. A, 684 (2017), 598. https://doi.org/10.1016/j.msea.2016.12.097

19) J. H. Kim, S. W. Lee, K. Lee, J.-K. Kim and D.-W. Suh: JOM, 71 (2019), 1366. https://doi.org/10.1007/s11837-019-03332-y

20) B. Jiang, X. Hu, L. Zhou, H. Wang, Y. Liu and F. Gou: Met. Mater. Int., (2019). https://doi.org/10.1007/s12540-019-00371-7

21) O. R. Terrazas, K. O. Findley and C. J. V. Tyne: ISIJ Int., 57 (2017), 937. https://doi.org/10.2355/isijinternational.ISIJINT-2016-602

22) Z. Lawrynowicz: Mater. Sci. Technol., 18 (2002), 1322. https://doi. org/10.1179/026708302225007259

$23)$ S. Lee, S.-J. Lee and B. C. De Cooman: Scr. Mater., 65 (2011), 225. https://doi.org/10.1016/j.scriptamat.2011.04.010

24) D. De Knijf, R. Petrov, C. Föjer and L. A. I. Kestens: Mater. Sci. Eng. A, 615 (2014), 107. https://doi.org/10.1016/j.msea.2014.07.054

25) D. P. Koistinen and R. E. Marburger: Acta Metall., 7 (1959), 59

26) S. Lee and B. C. De Cooman: Metall. Mater. Trans. A, 44 (2013), 5018. https://doi.org/10.1007/s11661-013-1860-2

27) F. G. Caballero and H. K. D. H. Bhadeshia: Curr. Opin. Solid State
Mater. Sci., 8 (2004), 251. https://doi.org/10.1016/j.cossms.2004.09.005 28) F. G. Caballero, M. K. Miller, S. S. Babu and C. Garcia-Mateo: Acta Mater., 55 (2007), 381. https://doi.org/10.1016/j.actamat.2006.08.033

29) F. G. Caballero, M. K. Miller, C. Garcia-Mateo, C. Capdevila and S. S. Babu: Acta Mater., 56 (2008), 188. https://doi.org/10.1016/ j.actamat.2007.09.018

30) Z. Xiong, P. J. Jacques, A. Perlade and T. Pardoen: Scr. Mater., 157 (2018), 6. https://doi.org/10.1016/j.scriptamat.2018.07.030

31) J. I. Yoon, J. Jung, H. H. Lee, G.-S. Kim and H. S. Kim: Met. Mater. Int., 22 (2016), 1009. https://doi.org/10.1007/s12540-016-6346-5

32) L. Chen, J. K. Kim, S. K. Kim, G. S. Kim, K. G. Chin and B. De Cooman: Steel Res. Int., 81 (2010), 552. https://doi.org/10.1002/ srin.201000044

33) K. Sugimoto, S. Hidaka, H. Tanino and J. Kobayashi: Metall. Mater. Trans. A, 48 (2017), 2237. https://doi.org/10.1007/s11661-017-4046-5

34) K. Sugimoto, K. Nakano, S.-M. Song and T. Kashima: ISIJ Int., 42 (2002), 450. https://doi.org/10.2355/isijinternational.42.450

35) K. Sugimoto, A. Kanda, R. Kikuchi, S. Hashimoto, T. Kashima and S. Ikeda: ISIJ Int., 42 (2002), 910. https://doi.org/10.2355/ isijinternational.42.910

36) S. K. Paul: Manuf. Lett., 20 (2019), 1. https://doi.org/10.1016/ j.mfglet.2019.02.003

37) B. S. Levy and C. J. Van Tyne: J. Mater. Eng. Perform., 21 (2012), 1205. https://doi.org/10.1007/s11665-011-9997-x

38) R. Comstock, D. Scherrer and R. Adamczyk: J. Mater. Eng. Perform., 15 (2006), 675. https://doi.org/10.1361/105994906X150830

39) Z. Milosevic and F. Moussy: Advanced Technology of Plasticity 1987, Vol. 2, Springer-Verlag, Berlin, (1987), 697.

40) J. H. Kim, Y. J. Kwon, T. Lee, K.-A. Lee, H. S. Kim and C. S. Lee: Met. Mater. Int., 24 (2018), 187. https://doi.org/10.1007/s12540-0177288-2

41) J. I. Yoon, J. Jung, H. H. Lee, J. Y. Kim and H. S. Kim: Met. Mater. Int., 25 (2019), 1161. https://doi.org/10.1007/s12540-019-00270-X

42) K. Kamibayashi, Y. Tanabe, Y. Takemoto, I. Shimizu and T. Senuma: ISIJ Int., 52 (2012), 151. https://doi.org/10.2355/ isijinternational.52.151

43) H. Bhadeshia and D. Edmonds: Met. Sci., 17 (1983), 411. https://doi. org/10.1179/030634583790420600

44) H. Bhadeshia and D. Edmonds: Met. Sci., 17 (1983), 420. https://doi. org/10.1179/030634583790420646

45) Y. Li and T. Baker: Mater. Sci. Technol., 26 (2010), 1029. https:// doi.org/10.1179/026708309X12512744154360

$46)$ K. Sugimoto, J. Sakaguchi, T. Iida and T. Kashima: ISIJ Int., 40 (2000), 920. https://doi.org/10.2355/isijinternational.40.920 